\title{
Improvement the voltage stability margin of Iraqi power system using the optimal values of FACTS devices
}

\author{
Ghassan Abdullah Salman, Hatim G. Abood, Mayyadah Sahib Ibrahim \\ Department of Electrical Power and Machines Engineering, College of Engineering, University of Diyala, Iraq
}

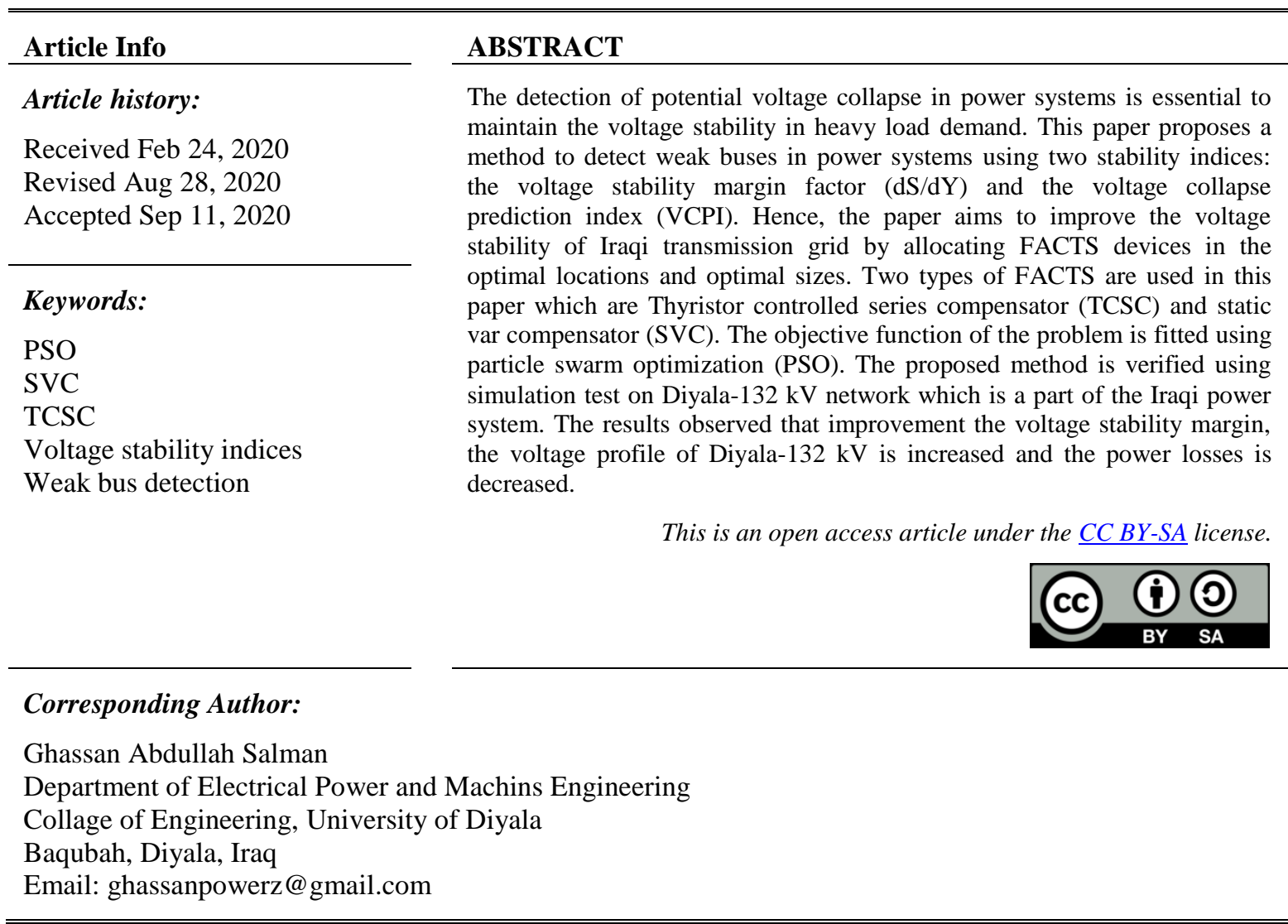

\section{INTRODUCTION}

Maintaining voltage stability of the power system is one of the major problems due to the frequent voltage collapse that is related to disturbances, over loaded systems and changing operating conditions. Therefore, the voltage point is known as a heavy loaded point [1-3]. The shortage in the capability of the system to meet the demand of the reactive power is the main reason of voltage profile deterioration. The system is considered unstable when the voltage magnitude of any bus decreases and the reactive power increases for the same bus of the system [4-7]. Therefore, the challenge is to identify weakest bus prone to voltage collapse and hence, initiates that the problem of voltage instability. The existing method of detecting the weak buses are almost based on voltage stability indices. However, the main way to avoid the voltage failure is to decrease the reactive power load or increase the systems' reactive power [8-11].

The flexible alternating current transmission system (FACTS) devices can achieve a safe and costeffective solution if they are appropriately installed in the power system. Among the entire FACTS devices, the Thyristor controlled series compensator (TCSC) and static var compensator (SVC) are selected to be applied in the proposed method due to their highly leading flexibility [12-18]. TCSC as an efficient series compensation controller can be utilized in transmission line, for control the power flow in power system, while SVC as an efficient shunt compensation controller can be injected reactive power at buses, for adjusted the voltages of power system [19-21]. Allocating these FACTS devices results in significant improvement in characteristic of voltage stability margin of the large-scale power systems [22-26]. In the existing literature, 
the optimal deployment of the FACTS devices is achieved using several optimization techniques such as the genetic algorithm (GA), evolutionary programming (EP) and particle swarm optimization (PSO) [27-32].

In this paper, a PSO-based methodology is proposing for finding the optimal sizes and selecting the optimal locations of the FACTS devices. However, this paper focuses on the setting and placement of TCSC and SVC controller, for improvement the voltage stability margin of Diyala $132 \mathrm{kV}$ power system. The proposed method aims to improve the voltage stability of the Iraqi power grid by installing the proposer FACTS devices in the weakest bus according to its voltage stability indices. Multi- objective functions are used in this paper relevant to the active power losses, voltage stability margin, and the voltage stability deviation are employed for optimizing the optimal locations and sizes of FACTS devices. Both TCSC and SVC be able of improving the voltage stability margin and therefore, enhancing the overall system performance.

The rest of the paper is organized as follows: the mathematical formulation of the voltage stability problem, the indices of voltage stability, and the modeling of the FACTS devices are given in section 2, the proposed method, formulation of the objective functions with the PSO algorithm is presented in section 3, simulation tests and discussion are provided in section 4 followed by the conclusions in section 5 .

\section{FORMULATION OF VOLTAGE STABILITY AND FACTS DEVICES}

This section provides the formulas of modeling the two indices of voltage stability margin with the detection techniques of the weakest bus and the modeling of the two types of FACTS devices. In this paper, the overall performance of power system is enhancement by using series and shunt FACTS devices which are the TCSC and SVC.

\subsection{Voltage stability margin factor $(\mathrm{dS} / \mathrm{dY})$}

The $(\mathrm{dS} / \mathrm{dY})$ index describes the voltage stability margin based on Thevenin theorem ranges from 0 (no-load) to 1 (voltage-collapse point). Based on this index, the voltage collapse point is reached when the $(\mathrm{dS} / \mathrm{dY})$ factor is close to zero. Hence, the weakest bus in system is the closest one to zero. However, the model is represented by the following equations $[8,9]$ :

$$
V=\frac{E_{T h} Z_{L}}{\sqrt{Z_{T h}^{2}+Z_{L}^{2}+2 Z_{T h} Z_{L} \cos (\theta-\varphi)}}
$$

The load is supplied by the apparent power,

$$
\begin{aligned}
& S=V^{2} Y \quad \text { where } Y=\frac{1}{Z_{L}} \\
& S=\frac{E_{T h}^{2} Z_{L}}{Z_{T h}^{2}+Z_{L}^{2}+2 Z_{T h} Z_{L} \cos (\theta-\varphi)} \\
& \frac{d S}{d Y}=\frac{E_{T h}^{2}\left(1-Z_{T h}^{2} Y^{2}\right)}{\left(1+Z_{T h}^{2} Y^{2}+2 Z_{T h} Y \cos (\theta-\varphi)\right)^{2}}
\end{aligned}
$$

where, $\theta$ is the phase angle of impedance $Z_{T h}$ and $\varphi$ is the phase angle of impedance $Z_{L}$.

\subsection{Voltage collapse prediction index (VCPI)}

The VCPI index is derived from the basic power flow equation to determine the voltage stability margin. The voltage collapse point is met when VCPI factor is close to one, and the weakest bus in system is that closest to one. However, the model can be represented as follows [10, 11]:

$$
V C P I_{k}=1-\frac{\sum_{\substack{m=1 \\ m \neq k}}^{N} V_{m}^{\prime}}{V_{k}}
$$

In (4) $V_{m}^{\prime}$ is represented by,

$$
V_{m}^{\prime}=\frac{Y_{k m}}{\sum_{\substack{j=1 \\ j \neq k}}^{N} Y_{k j}} V_{m}
$$


In this part, the load is increased regarding as loading factor $(\lambda)$ which leads to voltage collapse point of power systems.

$$
P_{L}=\lambda P_{L o} \quad, Q_{L}=\lambda Q_{L o}
$$

where, $V_{k}$ is the voltage phasor at bus $k, V_{m}$ is the voltage phasor at bus $m, Y_{k m}$ is the admittance between bus $k$ and $\mathrm{m}, Y_{k j}$ is the admittance between bus $k$ and $j, k$ is the monitoring bus, $m$ is the other bus connected to bus $k$ and $\lambda$ is the loading factor.

\subsection{Modelling of TCSC}

The TCSC is the series types of FACTS device and connected between two buses shown in Figure 1. The TCSC operates either inductive or capacitive by modification the reactance of transmission line, and the model can be represented by the following equations [23, 28]:

$$
\begin{aligned}
& X_{i j}=X_{L}+X_{T C S C} \\
& X_{T C S C}=r_{T C S C} * X_{L} \\
& -0.8 X_{L} \leq X_{T C S C} \leq 0.2 X_{L}
\end{aligned}
$$

where, $X_{L}$ is the reactance of the transmission line, $X_{T C S C}$ is the TCSC reactance and $r_{T C S C}$ is the coefficient depending on reactance of the transmission line location.

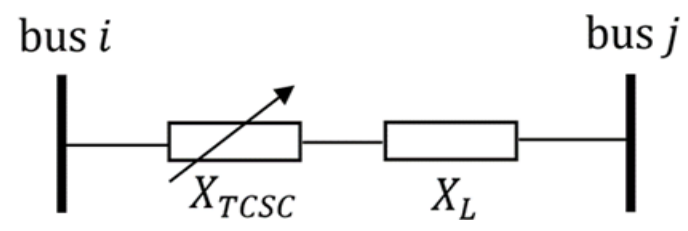

Figure 1. TCSC structure model

\subsection{Modelling of SVC}

The most popular configuration of shunt type connected FACTS device is the SVC that is shown in Figure 2. The SVC operates either capacitive or inductive by injection or absorbing reactive power to the bus, and the model can be represented as follows [23, 28]:

$$
\begin{aligned}
& I_{S V C}=j B_{S V C} V_{k} \\
& Q_{S V C}=-B_{S V C} V_{k}^{2} \\
& -100 \leq Q_{S V C} \leq 100
\end{aligned}
$$

where, $I_{S V C}$ is the current drawn by SVC, $V_{k}$ is the voltage at $k_{i t h}$ bus, $B_{S V C}$ is the susceptance of SVC and $Q_{S V C}$ is the reactive power injected into the bus (inductive or capacitive).

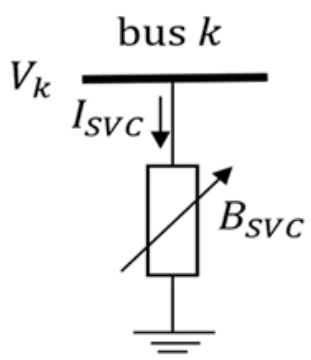

Figure 2. SVC structure model 


\section{PROPOSED METHODOLOGY}

In the proposed method, the optimal location and value of TCSC and SVC controller is determined by using PSO algorithm based on multi-objective functions.

\subsection{Formulation of multi-objective functions}

The optimal sizing and location of TCSC and SVC devices are found based on four objective functions. This paper proposes improved formulations to that described in [8-11, 24, 25]. The modifications implemented on the traditional indices is proposed in such a way that normalize the target of the objective functions and facilitate convergence of the problem. Two of the objective functions are minimized and two functions are maximized. The objective functions are summarized below:

\subsubsection{Power losses index (PLI)}

Based on this objective function, the active power losses are computed with and without FACTS controller. The PLI is minimized and can be formulated as [24, 25]:

$$
\begin{aligned}
& P_{L}=\sum_{k=1}^{N} G_{k}\left[V_{i}^{2}+V_{j}^{2}-2 V_{i} V_{j} \cos \delta_{i j}\right] \\
& P L I=P_{L}^{W}-P_{L}^{W O}
\end{aligned}
$$

where $P_{L}^{W}-P_{L}^{W O} \leq 0$. Where, $N$ is the number of transmission lines, $G_{k}$ is the conductance of branch between bus $i$ and bus $j, V_{i}$ is the voltage magnitude at bus $i, V_{j}$ is the voltage magnitude at bus $j, \delta_{i j}$ is the phase angle difference, $P_{L}^{W}$ is the total power losses with TCSC \& SVC and $P_{L}^{W O}$ is the total power losses without TCSC \& SVC.

\subsubsection{Voltage margin index (VMI)}

Based on this objective function, the voltage profile of load buses is computed, with and without FACTS controller. The acceptable values of bus voltage are $(1 \pm 0.5)$. The VMI is maximized and can be formulated as $[24,25]$ :

$$
V M I=\sum_{i \neq 1}^{P Q b u s}\left(V_{i}^{W}-V_{i}^{W O}\right)
$$

where $V_{i}^{W}-V_{i}^{W O} \geq 0$. Where, $V_{i}^{W}$ is the voltage magnitude with TCSC \& SVC and $V_{i}^{W O}$ is the voltage magnitude without TCSC \& SVC.

\subsection{3. dS/dY deviation $(\Delta d S / d Y)$}

This objective function computes the deviation of dS/dY for load buses with and without FACTS controller. The $\Delta \mathrm{dS} / \mathrm{dY}$ is maximized and can be formulated as $[8,9]$ :

$$
\Delta \frac{d S}{d Y}=\sum_{i \neq 1}^{P Q \text { bus }}\left[\left(\frac{d S}{d Y}\right)_{i}^{W}-\left(\frac{d S}{d Y}\right)_{i}^{W O}\right]
$$

where $\left(\frac{d S}{d Y}\right)_{i}^{W}-\left(\frac{d S}{d Y}\right)_{i}^{W O} \geq 0$. Where, $\left(\frac{d S}{d Y}\right)_{i}^{W}$ is the Voltage Stability Margin Factor with TCSC \& SVC and $\left(\frac{d S}{d Y}\right)_{i}^{W O}$ is the voltage stability margin factor without TCSC \& SVC.

\subsubsection{VCPI deviation ( $\triangle \mathrm{VCPI})$}

This objective function computes the deviation of VCPI for load buses with and without FACTS controller. The $\triangle \mathrm{VCPI}$ is minimized and can be formulated as $[10,11]$ :

$$
\Delta V C P I=\sum_{i \neq 1}^{P Q \text { bus }}\left(V C P I_{i}^{W}-V C P_{i}^{W O}\right)
$$

where $V C P I_{i}^{W}-V C P_{i}^{W O} \leq 0$. Where, $V C P I_{i}^{W}$ is the voltage collapse prediction index with TCSC \& SVC and $V C P_{i}^{W O}$ is the voltage collapse prediction index without TCSC \& SVC. Therefore, the objective function $(J)$ is given by:

$$
J=0.25 *\left(P L I-V M I-\Delta \frac{d S}{d Y}+\Delta V C P I\right)
$$




\subsection{Particle swarm optimization (PSO)}

Based on the PSO algorithm, the parameters of each particle are updated in each iteration according to the following formulas that are simulating the position and velocity of each bird in birds' swarms [33-35].

$$
\begin{aligned}
& V_{i}^{K+1}=W\left[V_{i}^{K}+\emptyset_{1} r_{1}\left(p_{\text {best }, i}^{K}-X_{i}^{K}\right)+\emptyset_{2} r_{2}\left(g_{\text {best }, i}^{K}-X_{i}^{K}\right)\right] \\
& X_{i}^{K+1}=X_{i}^{K}+V_{i}^{K+1} \\
& W=\frac{2}{2-\emptyset-\sqrt{\emptyset^{2}-4 \varnothing}}, \emptyset_{1}+\emptyset_{2}=\emptyset>4
\end{aligned}
$$

where, $X_{i}^{K+1}$ is the position of particle at $k+1, X_{i}^{K}$ is the position of particle at $k, V_{i}^{K+1}$ represent the velocity of the particle at $k+1, V_{i}^{K}$ represent the velocity of the particle at $k, W$ represent inertia weight parameter, $\emptyset_{1}$ and $\emptyset_{2}$ are two positive numbers called acceleration constants are usually set to be 2 and 2.1 respectively, and $r_{1}, r_{2}$ are random number in the interval $[0,1]$.

\subsubsection{Proposed algorithm}

The proposed PSO-based algorithm of allocating and sizing the FACTS devices for improving voltage stability is implemented as follows [36-38]:

Step 1: Specify the PSO parameters: initial velocity, number of particles and max iteration.

Step 2: Initialize FACTS location and sizing for each particle (TCSC or SVC controller.

Step 3: Run Newton Raphson power flow program and compute objective functions.

Step 4: Determine and store pbest and gbest for all particles.

Step 5: Cheek max iteration is reached (Yes or No), if Yes go to step 7, while if No go to step 6.

Step 6: Update velocity and particle position and repeat the process until to reach max iteration (go to step 3). Step 7: Print the store result (optimal placement and value of FACTS device).

Regarding TCSC, the particles are defined as a vector which contains the locations of (line number) and sizes of TCSC controller. Whereas, the SVC vector includes the SVC bus locations and their sizes as shown below $[6,32]$ :

$$
\begin{aligned}
& \text { Particle: [LlocN TCSCsi] } \\
& \text { Particle: [BlocN SVCsi] }
\end{aligned}
$$

where, LlocN is the line location number of TCSC, TCSCSi is the sizing of TCSC, BlocN is the bus location number of SVC and SVCsi is the sizing of SVC.

\section{SIMULATION TESTS}

The performance of the proposed algorithm is evaluated using simulations tests on Diyala 10-bus which is a part of the Iraqi $132 \mathrm{kV}$ power grid. The single-line diagram of the test system is shown in Figure 3. The data of Diyala 10-bus test system are given in [24-26]. MATLAB R2017a is used for implementing the algorithm. Two case studies are carried out to evaluate the proposed methodology before and after allocating of FACTS devices:

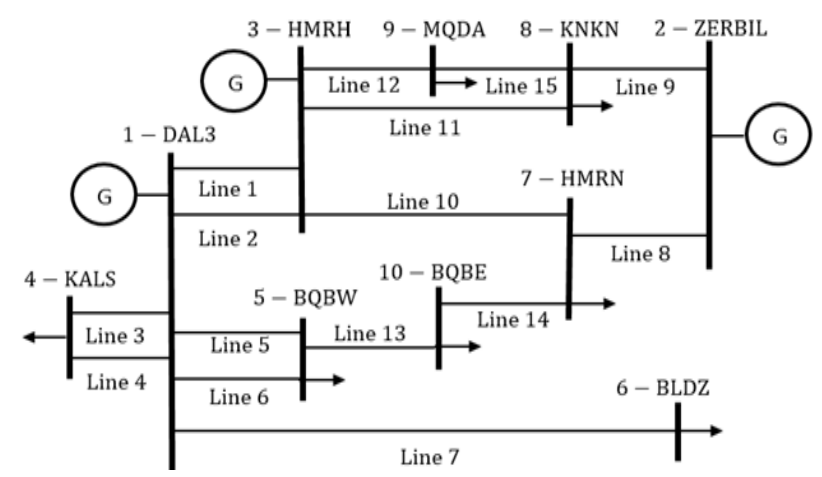

Figure 3. Single-line diagram of diyala 10-bus system $(132 \mathrm{kV})$ 


\subsection{Detection of the weakest bus}

In order to study the voltage collapse point and detect weakest bus in the system, the voltage stability margin are carried out on Diyala 10-bus test system with two types of stability index: (dS/dY) and VCPI. Regarding the first index (dS/dY), the load admittance of the test system is increased in a range of six steps (from the base case of the load to six times of the load). The incremental increasing of the system's load while applying first index leads to the response shown in Figure 4 which reveals the rank of the buses according their voltage collapse. The weakest bus is the closest one to zero which is BLDZ bus.

On the other hand, for the VCPI index, the load (active and reactive parts) of the test system is increased in steps from the base load to four times of the base load. Applying the VCPI while increasing the load results in the response of the buses according to their voltage collapse as shown in Figure 5. Again, BLDZ bus is the weakest bus as it is the closest to one. Overall, the rank ordering of the system buses according to their response to voltage collapse without FACT devices is as shown in Table 1.

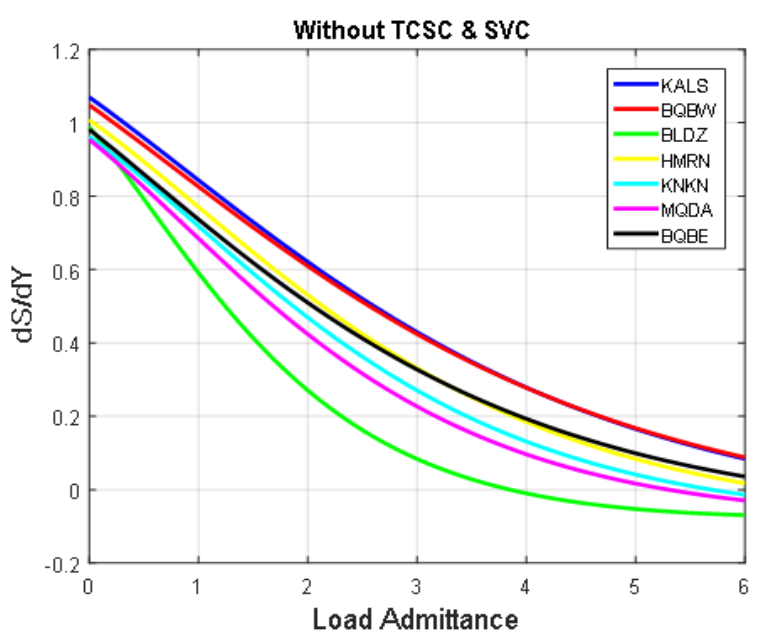

Figure 4. dS/dY vs load admittance

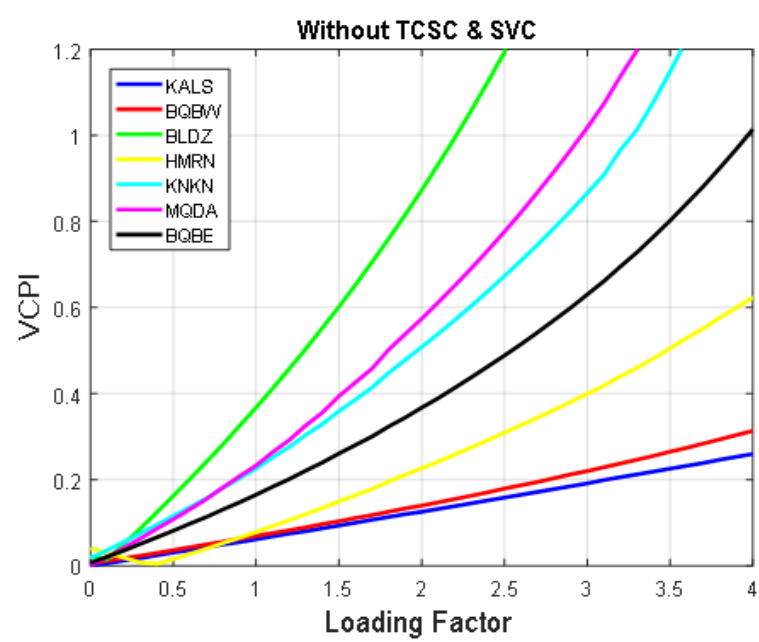

Figure 5. VCPI vs loading factor

Table 1. Weakest bus ranking

\begin{tabular}{cccccccc}
\hline Rank order & 1 & 2 & 3 & 4 & 5 & 6 & 7 \\
\hline dS/dY & BLDZ & MQDA & KNKN & HMRN & BQBE & KALS & BQBW \\
VCPI & BLDZ & MQDA & KNKN & BQBE & HMRN & BQBW & KALS \\
\hline
\end{tabular}

\subsection{Allocating the FACTS devices}

The proposed PSO-based algorithm is executed for multiple iterations to determine the optimal placement and sizing of FACTS devices meet the optimization constraints. The number of populations is 20 and the maximum iteration is 30. Regarding the improvement of voltage stability margin, both TCSC and SVC controllers are employed in this paper. The PSO algorithm is used to generate the optimal location and sizing of TCSC and SVC controllers by minimizing the objective function of (18).

From the single-line diagram of Diyala 10-bus power system is shown in Figure 3, all the single line circuits (from line 7 to line 15) are assigned locations for installing the TCSC controller. Therefore, line 7 and line 15 are represented for minimum and maximum location number of TCSC respectively. Similarly, all the load buses (from bus 4 to bus 10) are chosen locations for injection the SVC controller and therefore, bus 4 and bus 10 are assigned for minimum and maximum location number of SVC respectively. Based on the proposed method, the optimal values and placements of TCSC and SVC devices are shown in Table 2.

Table 2. Locations and sizing of TCSC and SVC

\begin{tabular}{cccccccc}
\hline \multirow{2}{*}{ TCSC } & Location (Line) & $\mathrm{X}_{\text {TCSC }}$ size (p.u.) & PLI & VMI & $\Delta \mathrm{dS} / \mathrm{dY}$ & $\Delta$ VCPI & $\mathrm{J}$ \\
& DAL3-BLDZ & -0.1117 & -0.028 & 0.024 & 0.478 & -0.247 & -0.194 \\
\hline \multirow{2}{*}{ SVC } & Location (Bus) & Qsvc size (Mvar) & PLI & VMI & $\Delta \mathrm{dS} / \mathrm{dY}$ & $\Delta$ VCPI & $\mathrm{J}$ \\
& MQDA & 51.005 & -0.656 & 0.070 & 0.236 & -0.202 & -0.291 \\
\hline
\end{tabular}


The enhancement of the test system performance due to utilizing the FACTS devices (TCSC and SVC) is demonstrated in the Figures 6 and 7 using the response to the two indices (dS/dY and VCPI). From Figure 6, it is evident that the voltage stability margin of BLDZ bus is improved as the voltage collapse point become higher which refers to more flexibility toward overloading and hence, load shedding case. On the other hand, the VCPI is also improved as it becomes more stable on load increasing as shown in Figure 7.

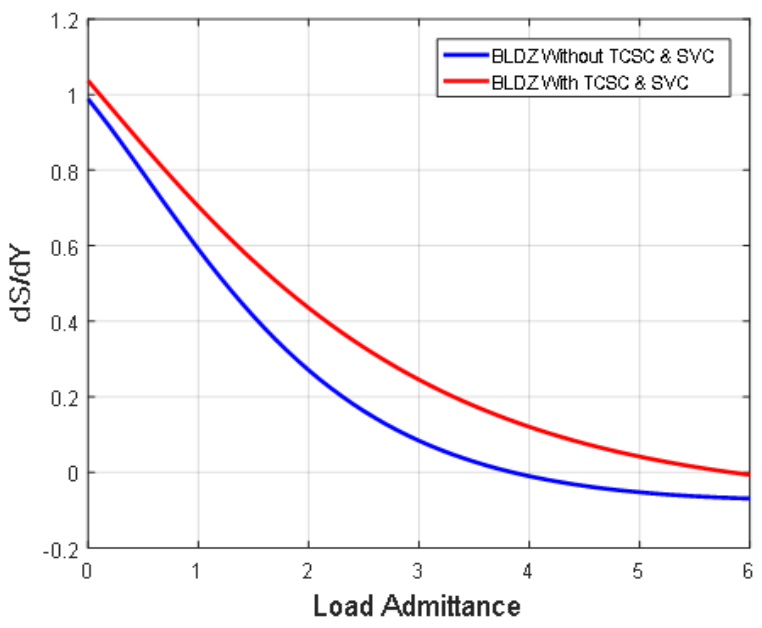

Figure 6. dS/dY vs load admittance at BLDZ bus

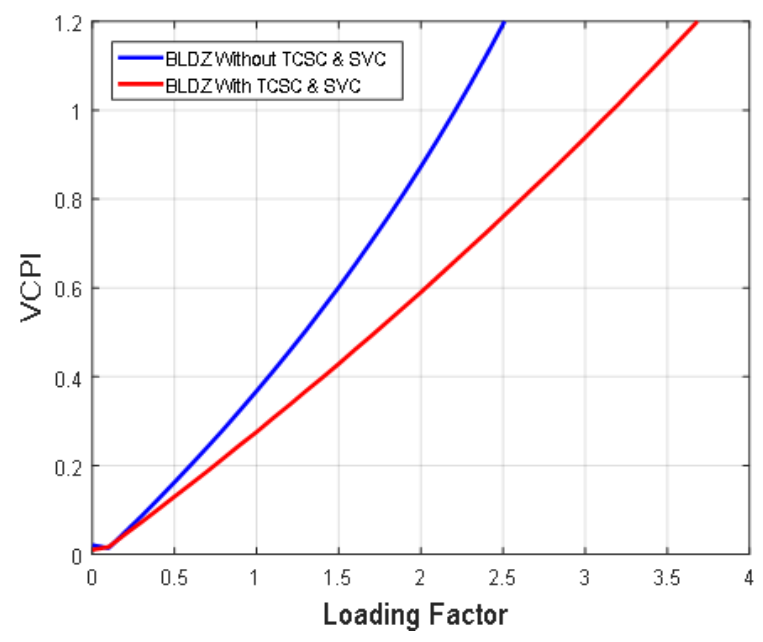

Figure 7. VCPI vs loading factor at BLDZ bus

Figure 8 illustrates the behavior of the objective function to determine the optimal values and locations of TCSC and SVC controller during the optimization process. It can be observed that the SVC has minimum and faster convergence compared with TCSC to achieve the objective function. Furthermore, the overall performance is improved for the whole buses of the system by enhanced the voltage profile, phase angle difference and power losses. Figure 9 illustrates the voltage profile of the test system before and after installing the FACTS devices where the voltages of buses BLDZ, MQDA and KNKN are significantly enhanced. Whereas, the results show that the percentage reduction rate of power losses is $7.22 \%$.

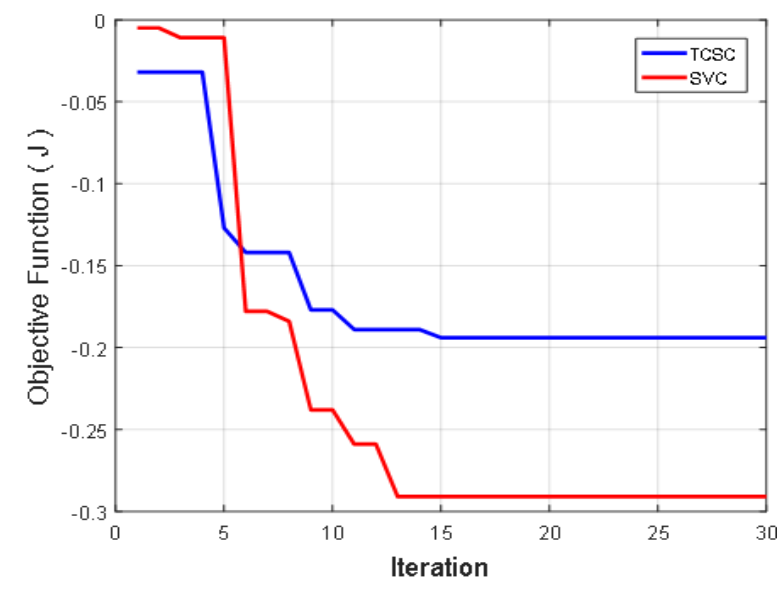

Figure 8. Convergence rate of the objective function

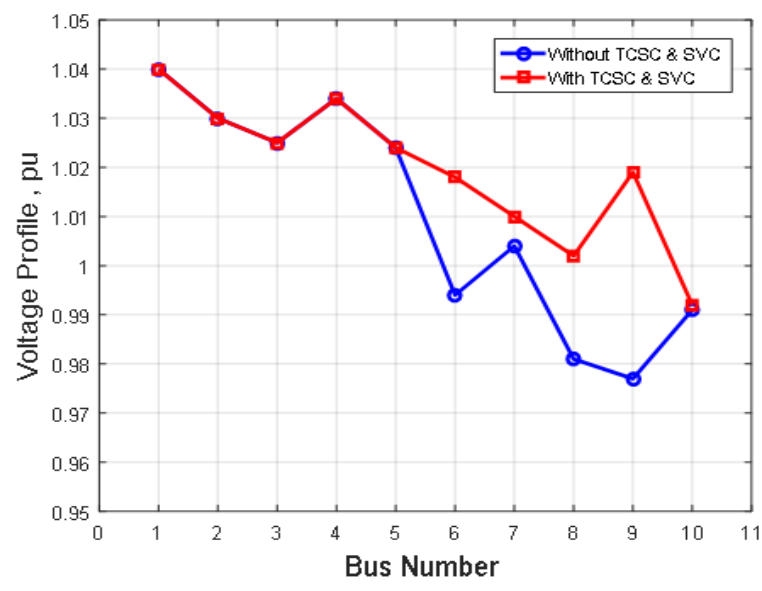

Figure 9. Voltage profile of diyala 10-bus

\section{CONCLUSION}

The paper proposes a methodology to detect the weakest bus of power systems using two indices: first is the voltage stability margin factor $(\mathrm{dS} / \mathrm{dY})$ and second is the voltage collapse prediction index (VCPI). The propose method utilizes a PSO-based algorithm to select the optimal locations and ratings of FACTS devices. The results show that the weakest bus in Diyala-10 bus power network is BLDZ. Based on the 
proposed method, the optimal location of TCSC is line (DAL3-BLDZ). Whereas, the optimal location of SVC is MQDA bus. Both TCSC and SVC show capability to improve the voltage profile of the power system, reducing the power losses, and enhancing the overall performance of the system by reducing the phase angles difference. The optimization results show that the PSO algorithm provides validate solutions when implemented for FACTS devices on power systems.

\section{REFERENCES}

[1] C. W. Taylor, "Power System Voltage Stability," New York, McGraw-Hill, 1994.

[2] P. Kundur, et al., "Definition and Classification of Power System Stability," IEEE Transactions on Power Systems, vol. 19, pp. 1387-1401, 2004

[3] S. Kihwele, "Enhancement of Voltage Stability Margin Using FACTS Devices for $132 \mathrm{kV}$ Tanzania Grid Network," IEEE International Conference on Electronics, Information, and Communication, 2019, pp. 1-3.

[4] T. He, et al., "Identification of weak locations in bulk transmission systems using voltage stability margin index," International Conference on Probabilistic Methods Applied to Power Systems, 2004, pp. 878-882.

[5] S. A. Soliman, et al., "Power System Voltage Stability Margin identification Using Local Measurements," Large Engineering Systems Conference on Power Engineering, 2003, pp. 100-104.

[6] S. Chansareewittaya and P. Jirapong, "Power transfer capability enhancement with multitype FACTS controllers using hybrid particle swarm optimization," Electrical Engineering, vol. 97, pp. 119-127, 2015.

[7] S. K. A. Hassan and F. M. Tuaimah, "Optimal location of unified power flow controller genetic algorithm based," International Journal of Power Electronics and Drive Systems (IJPEDS), vol. 11, no. 2, pp. 886-894, 2020.

[8] A. Wiszniewski, "New criteria of voltage stability margin for the purpose of load shedding," IEEE Transactions on Power Delivery, vol. 22, pp. 1367-1371, 2007.

[9] A. R. Phadke, et al., "A new technique for on-line monitoring of voltage stability margin using local signals," in Fifteenth National Power Systems Conference, 2008, pp. 488-492.

[10] V. Balamourougan, et al., "Technique for online prediction of voltage collapse," IEE Proceedings-Generation, Transmission and Distribution, vol. 151, 2004, pp. 453-460.

[11] M. Nizam, et al., "Dynamic voltage collapse prediction on a practical power system using power transfer stability index," IEEE 5th Student Conference on Research and Development, 2007, pp. 1-6.

[12] J. Lakkireddy, et al., "Steady state voltage stability enhancement using shunt and series FACTS devices," IEEE Clemson University Power Systems Conference, 2015, pp. 1-5.

[13] A. Sode-Yome, et al., "A comprehensive comparison of FACTS devices for enhancing static voltage stability," 2007 IEEE Power Engineering Society General Meeting, 2007, pp. 1-8.

[14] M. A. Kamarposhti and H. Lesani, "Effects of STATCOM, TCSC, SSSC and UPFC on static voltage stability," Electrical Engineering, vol. 93, pp. 33-42, 2011.

[15] M. Zadehbagheri, et al., "Review of the UPFC Different Models in Recent Years," International Journal of Power Electronics and Drive Systems (IJPEDS), vol. 4, no. 3, pp. 343-355, 2014.

[16] I. Azim and F. Rahman, "Genetic Algorithm Based Reactive Power Management by SVC," International Journal of Electrical and Computer Engineering (IJECE), vol. 4, no. 2, pp. 200-206, 2014.

[17] C. Li, et al., "Optimal allocation of multi-type FACTS devices in power systems based on power flow entropy," Journal of Modern Power Systems and Clean Energy, vol. 2, pp. 173-180, 2014.

[18] N. Yorino, et al., "A new formulation for FACTS allocation for security enhancement against voltage collapse," IEEE Transactions on Power Systems, vol. 18, pp. 3-10, 2003.

[19] S. Mollazei, et al., "Multi-objective optimization of power system performance with TCSC using the MOPSO algorithm," 2007 IEEE Power Engineering Society General Meeting, Tampa, FL, 2007, pp. 1-8.

[20] R. Minguez, et al., "Optimal Network Placement of SVC Devices," IEEE Transactions on Power Systems, vol. 22, no. 4, pp. 1851-1860, 2007.

[21] B. Kumar, et al., "Placement of FACTS controllers using modal controllability indices to damp out power system oscillations," IET Generation, Transmission \& Distribution, vol. 1, pp. 209-217, 2007.

[22] N. Sharma, et al., "A novel placement strategy for FACTS controllers," IEEE Transactions on Power Delivery, vol. 18, pp. 982-987, 2003.

[23] M. A. Kamarposhti, et al., "Comparison of SVC, STATCOM, TCSC, and UPFC Controllers for Static Voltage Stability Evaluated by Continuation Power Flow Method," IEEE 8th Annual Electrical Power \& Energy Conference, Vancouver, BC, 2008, pp. 1-8.

[24] G. A. Salman, et al., "Implementation Optimal Location and Sizing of UPFC on Iraqi Power System Grid (132 kV) Using Genetic Algorithm," International Journal of Power Electronics and Drive Systems (IJPEDS), vol. 9, no. 4, pp. 1607-1615, 2018.

[25] G. A. Salman, "Implementation SVC and TCSC to Improvement the Efficacy of Diyala Electric Network (132 kV)," American Journal of Engineering Research (AJER), vol. 4, pp. 163-170, 2015.

[26] H. I. Hussein, et al., "Phase Measurement Units based FACT's Devices for the Improvement of Power Systems Networks Controllability," International Journal of Electrical and Computer Engineering (IJECE), vol. 8, no. 2, pp. 888-899, 2018.

[27] K. Venkateswarlu, et al., "Improvement of Voltage Stability and Reduce Power Losses by Optimal Placement of UPFC device by using GA and PSO," International Journal of Engineering Sciences Research, vol. 1, no. 2, pp. 66-75, 2001. 
[28] S. Gerbex, et al., "Optimal location of multi-type FACTS devices in a power system by means of genetic algorithms," IEEE Transactions on Power Systems, vol. 16, pp. 537-544, 2001.

[29] C. Rodríguez and M. A. Rios, "Sizing and location of shunt FACTS devices in power system using genetic algorithms," 2013 IEEE Grenoble Conference, Grenoble, 2013, pp. 1-6.

[30] W. Ongsakul and P. Jirapong, "Optimal allocation of FACTS devices to enhance total transfer capability using evolutionary programming," Proceedings of the IEEE International Symposium on Circuits and Systems (ISCAS), vol. 5, 2005, pp. 4175-4178.

[31] H. Shaheen, et al., "Optimal location and parameters setting of unified power flow controller based on evolutionary optimization techniques," Proceedings of the IEEE Power Engineering Society General Meeting, 2007, pp. 1-8.

[32] D. Mondal, et al., "Optimal placement and parameter setting of SVC and TCSC using PSO to mitigate small signal stability problem," International Journal of Electrical Power \& Energy Systems, vol. 42, pp. 334-340, 2012.

[33] J. Kennedy and R. Eberhart, "Particle swarm optimization in," Proceedings of the IEEE International Conference on Neural Networks, 1995, pp. 1942-1948.

[34] J. Kennedy and R. Mendes, "Neighborhood topologies in fully-informed and bestof-neighborhood particle swarms," IEEE International Workshop on Soft Computing in Industrial Applications, 2003, pp. 45-50.

[35] Y. del Valle, et al., "Particle Swarm Optimization: Basic Concepts, Variants and Applications in Power System," IEEE Transactions on Evolutionary Computation, vol. 12, pp. 171-195, 2008.

[36] G. A. Salman, et al., "Enhancement The Dynamic Stability of The Iraq's Power Station Using PID Controller Optimized by FA and PSO Based on Different Objective Functions," Elektrotehniški Vestnik, vol. 85, pp. 42-48, 2018.

[37] H. I. Hussein, et al., "Employment of PSO algorithm to improve the neural network technique for radial distribution system state estimation," International Journal on Smart Sensing and Intelligent Systems, vol. 12, pp. 1-10, 2019.

[38] G. A. Salman, et al., "Application of artificial intelligence techniques for LFC and AVR systems using PID controller," International Journal of Power Electronics and Drive Systems (IJPEDS), vol. 10, no. 3, pp. 1694-1704, 2019 .

\section{BIOGRAPHIES OF AUTHORS}

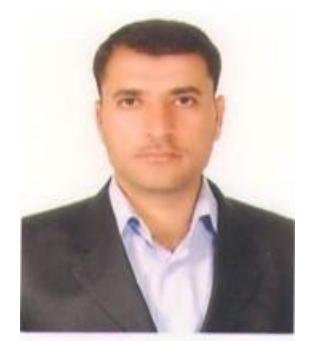

Ghassan Abdullah Salman received his B.Sc. degree in engineering of Power and Electrical Machines in 2006 from the University of Diyala. He received his M.Sc. degree in Electrical Power engineering in 2011 from the University of Technology, Baghdad, Iraq. Currently, he is an Assistant Professor at University of Diyala, Baqubah, Iraq. His research focuses on power system optimization, power system operation and control, FACTS devices, power system security and power system stability.

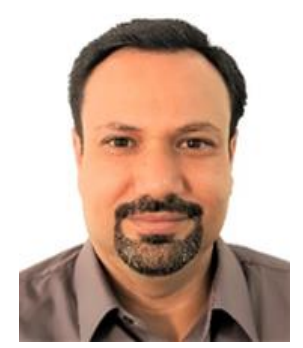

Hatim Ghadhban Abood had graduated at the University of Diyala in 2006, majoring in Electrical Power Engineering. He had received the degree of M.Sc. in Electrical Power engineering from the University of Technology, Baghdad, Iraq, in 2009. He works as a lecturer in the college of Engineering, Diyala university since April 2012. Later, Hatim finished the Ph.D. at The University of Western Australia, Perth, Australia in April 2018. His research focuses on power system state estimation, and applications of artificial intelligence techniques in power systems.

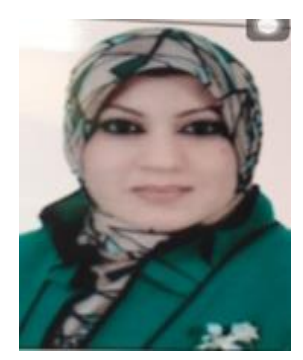

Mayyadah Sahib Ibrahim received her B.Sc. degree in engineering of Power and Electrical Machines in 2004 from the University of Diyala. She received his M.Sc. degree from technical state university of southern Russia in 2013. She is currently an Assistant Lecturer at University of Diyala, Baqubah, Iraq. Her current research interests are optimization of power system, electrical machine and programmable logic controller. She has experience in practice of electrical engineering in different fields such as electrical machines. 